\title{
ENERGY POTENTIAL FROM MUNICIPAL SOLID WASTE (MSW) FOR A DEVELOPING METROPOLIS
}

\author{
A.T. Akinshilo ${ }^{1, *}$, J.O. Olofinkua ${ }^{1}$, O. Olamide ${ }^{2}$, E.A. Asuelinmen ${ }^{3}$
}

\begin{abstract}
In many developing cities around the world, the shortage of energy and environmental degradation are currently two vital issues affecting sustainable development. The migration of people from villages to one of Africa's rapidly growing city Lagos, Nigeria has led to the generation of tons of municipal solid waste (MSW) daily. This is one of the important contributors to environmental degradation. Harnessing the useful potential of MSW for power generation adopting the incineration technology will enhance the intermittent power supply and also help with waste management, which has threatening effect on the populace. Therefore this paper focuses on energy stored in waste generated and the power potential of this MSW through an energy recovery method to generate other forms of energy for use has an alternative energy. From the waste characterization exercise, the main components of the Lagos MSW were found to be food, metal and plastic; making the average moisture content of the MSW high. It was illustrated from analysis that a high power potential of over 10,000 MW can be obtained adopting the incineration process, starting with data from 2016 with an exponential increase over the years.
\end{abstract}

Keywords: Solid Municipal Waste, Site Selection, Waste Forecast, Energy Recovery Potential, Lagos Metropolis

\section{INTRODUCTION}

Waste arises from human activities such as domestic, commercial, industrial, agricultural and so on. These wastes if channeled to resourceful applications can make meaningful contribution to energy generation but when not properly utilized, it will have a negative impact on the living conditions. Municipal solid waste contains glass, paper, plastic, food waste amongst other putrescible. A wide range of substrates are available for conversion to bio-energy. The most commonly used methods include incineration, biomethanation/anaerobic digestion and gasification [1- 4]. The incineration technology involves burning of solid waste which is capable of reducing waste to $70 \%$ by mass and $90 \%$ by volume, producing steam for electricity and cogeneration. Biomethanation or anaerobic digestion process, an environmentally friendly energy conversion process utilizes micro-organism in decomposing biomass to produce biogas which may be used for combined heat and power generation while the gasification process involves the partial combustion of shredded wastes to generate biogas. However several solid waste mainly agricultural produce, wood and plastics are types of waste that can be gasified without pre-treatment, the producer gas obtained is used for energy production.

In the effort to study power production Omari [5] carried out a thorough characterization of municipal solid waste of the city of Arusha, Tanzania where he showed the higher heating value, thermo-degradation analysis to determine the activation energy. The possibility of increasing the energy production was investigated by Alex [6] using waste through the solid waste to energy advanced thermal technology system and analytical cost models. Porteus [7] did a review of energy generation from waste incineration with emphasis on the effect of greenhouse gas emissions which is compared with emerging practices such Pyrolysis and gasification. [8-9] presented a review of energy recovery from burning solid municipal waste; where they reviewed the use of energy component obtained in form of steam, electricity or sale as solid fuel. Kalanatarifard [10] evaluated the composition and characteristics of solid waste for the purpose of obtaining information about the quantity of plastic that can be recovered at Bukit Bakin landfill, Malaysia. Gohlke [11] presented how greenhouse gas produced as a result of waste treatment can be

This paper was recommended for publication in revised form by Regional Editor Jaap Hoffman Hoffman

${ }^{1}$ Mechanical Engineering Department, University of Lagos, Akoka-Yaba, Nigeria.

${ }^{2}$ Mechanical Engineering Department, Federal University of Agriculture Abeokuta, Nigeria.

${ }^{3}$ Architecture Department, University of Lagos, Akoka-Yaba, Nigeria

*E-mail address: ta.akinshilo@gmail.com

Orcid id: 0000-0002-6436-3420, 0000-0003-4873-7864, 0000-0001-6197-0359, 0000-0003-2193-0883

Manuscript Received 28 October 2017, Accepted 04 March 2018 
described in simplified manner using energy indications. Themelis et al. [12] presented a study that showed technology implications of managing municipal solid waste in New York, they showed that Waste to Energy (WTE) processing of solid municipals reduces fuel consumption and is better compared to landfilling. Koten [19] evaluated the performance of diesel engine within multi-dimensional framework in the bid to determine it optimal power generation while Abay et al. [20] presented flow and combustion of diesel engines utilizing computational fluid dynamics techniques. Improvement of renewables power quality and control was investigated by Dehini and Berbaoul [21] adopting the multilayered feed forward scheme.

With respect to past research, the present paper aim to investigate the energy potential from solid municipal waste which may be obtained from landfills in Lagos state, Nigeria due to its peculiarity, as the commercial center of Africa, its rapid urbanization, meteoric population rise and problem of proper waste disposal methods. Therefore the potential in municipal solid waste for energy generation could serve as a source of alternative energy to the intermittent power supply experience across the state.

\section{SITE SELECTION}

The site selection for any waste to energy (WTE) technology which could be incinerator plants with energy recovery, biomethanation/ anaerobic digestion or gasification should be based on factors other than the mere availability of land due to the effect of carbon footprints on high population density. For most developing countries the practice as being mass burning of wastes i.e. to have an open piece of land for burning the large amount of waste produced daily. This practice has produced it numerous environmental effects such as environmental degradation and spread of contagious diseases. Environmental impact of waste to energy facilities are observed in the reduction of landfills as well as gas emissions. Thermal process involved in the combustion of MSW leads to incomplete thermal reactions leading to the release of heavy metals and harmful gases from MSW incinerators. Most notable are Dioxin/furans which are classes of chlorinated organics. These compound been found in incinerator stacks have been proven to be highly toxic on wildlife and human occupation. Although utilization of incinerator in a metropolis such as Lagos State requires the satisfaction of Federation environmental laws such as 247 criminal code Act CAP C38 LFN, 2004. Making it an offence to pollute air in a manner noxious to human health. However organic compounds emission can be destroyed during combustion process by adopting efficient incinerator design to achieve complete oxidation of hydrocarbon species and the use of air pollution control mechanism to bring to bearest minimal organic compound escaping the incinerator stack such that human life and environment are not threatened.

The design of the WTE site significantly impacts the cost of the facility, the control and the efficiency of the truck traffic flow. Location of a site can significantly affect dispersion of the plume from the chimney in the case of the incinerator, which in turn affects ambient concentrations, disposition and exposures to workers and the community. The population needs to be studied to determine the density and projected estimate for a known period into the future taking into consideration its mode of population growth. This information needs to be available because of it necessity knowing that population determine to a large extent the amount of waste to be considered and therefore total incineration needs of the community, both present and future. The following are some other factors that need to be considered in site selection for a WTE technology: Present and anticipated use of the land in the neighborhood under consideration, Accessibility of the location, Present and projected needs of the community, Availability of nearby areas requiring landfill, Coordinated road network around the intended plant and plants should be at least 300 to 500 meters from residential zones.

Based on the above considerations with respect to geomorphological terrains of Lagos state. Ibeju Lekki, Ikorodu and Ojo Local government areas are the most suitable location for waste to energy (WTE) site having a low population density [15], accessible road network and nearness to coastal regions. 

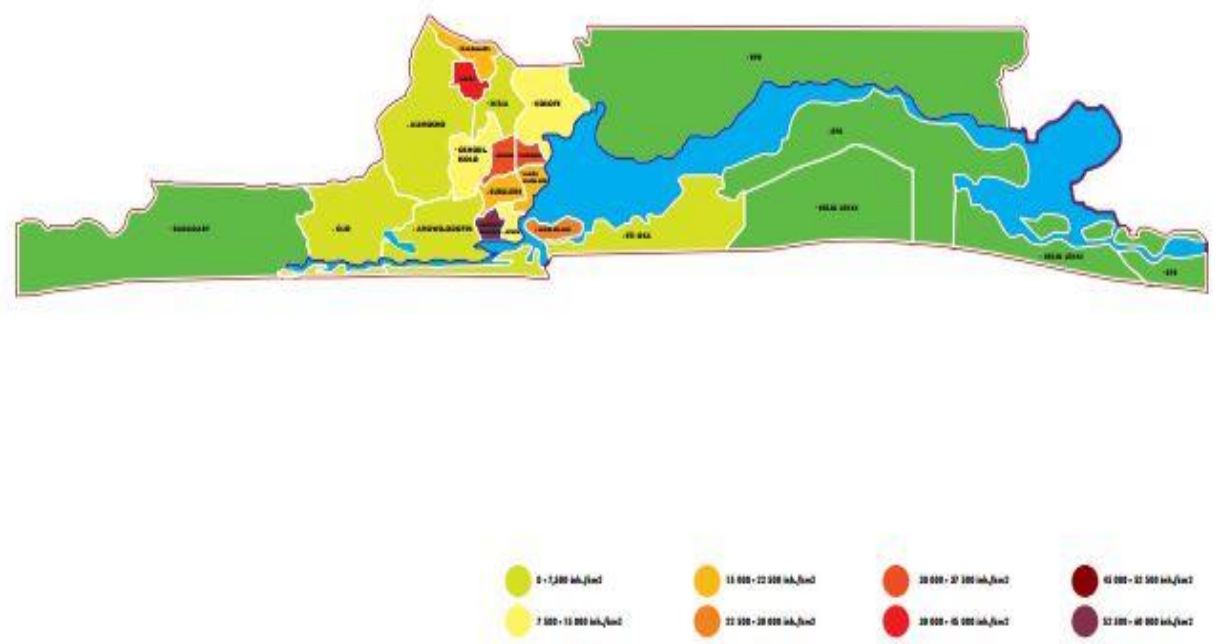

Figure 1. Map of Lagos state showing population density of local government

\section{WASTE GENERATION FORECAST}

Waste incinerators are used to destroy solids, sludge's, liquids, and tars. Depending upon the physical, chemical characteristics of the waste and the handling they require. It been estimated that the average waste generated per person per day is about $0.65 \mathrm{~kg} /$ person/day [13], with a growing population of about $18,000,000$ as at year 2015 with an increase rate in population of about $3.2 \%$ [15]. Therefore the amount of solid municipal waste generated daily with the population growth rate can be projected as follow in the Table 1, assuming the average waste generated per person remains constant. It obvious there will be an increasing amount of solid waste available throughout the state as shown on Table 1, which will create a chronic problem for residents if not properly and efficiently managed. However these massive quantity of solid municipal waste though largely wet are good source of Refuse derived fuels for electricity generation.

Table 1. Trend in waste generation

\begin{tabular}{|c|c|c|c|}
\hline Year & Population & Waste/day $(\mathrm{kg})$ & Waste/year (Ton) \\
\hline 2015 & 18000000 & 11700000 & 4270500 \\
\hline 2016 & 18576000 & 12074400 & 4407156 \\
\hline 2017 & 19170432 & 12460780 & 4548185 \\
\hline 2018 & 19783886 & 12859526 & 4693727 \\
\hline 2019 & 20416970 & 13271031 & 4843926 \\
\hline 2020 & 21070313 & 13695704 & 4998932 \\
\hline 2021 & 21744563 & 14133966 & 5158898 \\
\hline 2022 & 22440389 & 14586253 & 5323982 \\
\hline 2023 & 23440389 & 15053013 & 5494349 \\
\hline 2024 & 23899553 & 15534709 & 5670169 \\
\hline 2025 & 24664339 & 16031820 & 5851614 \\
\hline 2026 & 25453598 & 16544839 & 6038866 \\
\hline 2027 & 26268113 & 17074273 & 6232110 \\
\hline 2028 & 27108692 & 17620650 & 6431537 \\
\hline 2029 & 27976171 & 18184511 & 6637347 \\
\hline 2030 & 28871408 & 18766415 & 6849742 \\
\hline
\end{tabular}


With the rapid increase in waste generation across various parts of the state over the years, the tonnage of combustible waste can be used to support the electric power production across the state. This will further boost developmental projects, assist small and medium enterprises, and also complement the intermittent power supply from the various electricity distribution companies.

\section{ENERGY POTENTIAL FROM MUNICIPAL SOLID WASTE}

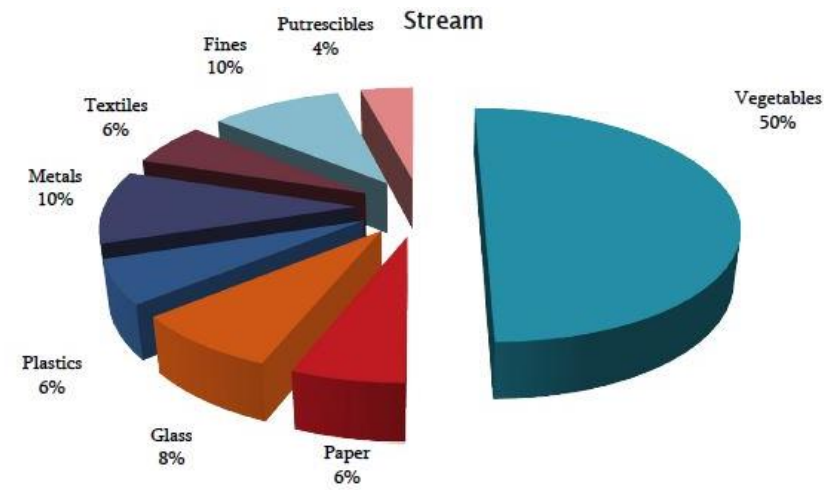

Figure 2. Chart showing the waste structure of Lagos State [13]

The bulk of solid waste in Lagos state are food wastes as shown in Figure 2 which as high moisture content. This is due to the lack of proper waste treatment and disposal method. However a high tonnage of waste is available for energy generation which will be of immense benefits to both domestic and commercial/industrial consumption.

\section{Estimation of Carbon Component of Solid Waste}

The combustion product of solid municipal waste which is mainly carbon $(\mathrm{C})$, hydrogen $(\mathrm{H})$, oxygen $(\mathrm{O})$, nitrogen $(\mathrm{N})$ and sulphur $(\mathrm{S})$ with its molecular weight is expressed in Table 2 with the ultimate analysis of flue gas of various solid waste compositions given in Table 3 .

Table 2. Molar composition of the waste yields [16]

\begin{tabular}{|c|c|c|c|c|c|}
\hline Combustibles & $\mathrm{C}$ & $\mathrm{H}$ & $\mathrm{O}$ & $\mathrm{N}$ & $\mathrm{S}$ \\
\hline Mass, $\mathrm{Kg}$ & 255.5 & 32.2 & 178.3 & 7.7 & 0.85 \\
\hline Moles/Kg & 12.01 & 1.01 & 16.00 & 14.01 & 32.06 \\
\hline Moles & 3066 & 34 & 3080 & 108 & 27 \\
\hline
\end{tabular}

Table 3. Ultimate analysis of solid municipal waste [16]

\begin{tabular}{|c|c|c|c|c|c|}
\hline Combustibles & $\mathrm{C}$ & $\mathrm{H}$ & $\mathrm{O}$ & $\mathrm{N}$ & $\mathrm{S}$ \\
\hline Vegetables & 48 & 6.4 & 37.6 & 2.6 & 0.4 \\
\hline Paper & 43.5 & 6.0 & 44 & 0.3 & 0.2 \\
\hline Plastic & 60 & 7.2 & 22.8 & & \\
\hline Textiles & 55 & 6.6 & 31.2 & 4.6 & 0.15 \\
\hline Others $^{\mathrm{a}}$ & 49.0 & 6.0 & 42.7 & 0.2 & 0.10 \\
\hline Total & 255.5 & 32.2 & 178.3 & 7.7 & 0.85 \\
\hline \multicolumn{7}{|c}{ a: putrescible,glass,fines, etc. }
\end{tabular}

Here we proceed by determining the various proportions in solid municipal waste generated across the state per year (tonnage) as shown in the Table 1 using the waste structure of Lagos state as illustrated in the Figure 2. Thereafter the carbon component of the various waste structure is determined with respect to the ultimate analysis of solid municipal waste in Table 3, where it can be easily shown from analysis that $1 \mathrm{~kg}$ of municipal solid waste will 
Journal of Thermal Engineering, Technical Note, Vol. 5, No. 6, Special Issue 10, pp. 196-204, December, 2019

generate $0.6683 \mathrm{~kg}$ of Carbon i.e. 1 tonnage of MSW will generate $668.3 \mathrm{~kg}$ of carbon. This is illustrated in the Figure 3 below.

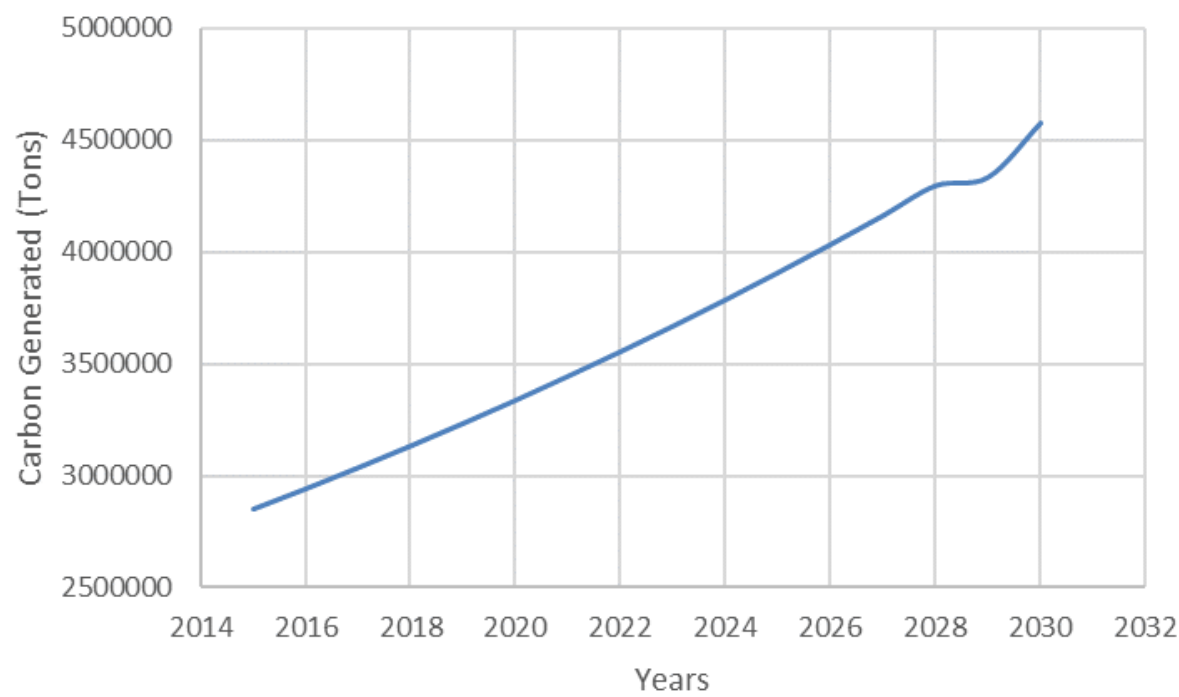

Figure 3. Analysis of Carbon component in Lagos State solid waste

The Figure 3 which shows the yearly generation of carbon constituent in tons from solid waste illustrates that the yearly Carbon constituent increases steadily due to the increase in waste generation across the state.

\section{Estimation of Methane $\left(\mathrm{CH}_{4}\right)$ from Carbon Generation}

$$
\mathrm{C}+2 \mathrm{H}_{2} \mathrm{O} \longrightarrow \mathrm{CH}_{4}+2 \mathrm{O}_{2}
$$

From the above chemical reaction, it can be demonstrated that 1 mole of carbon (C) reacting with 2 moles of water will yield 1 mole of Methane, releasing 2 moles of oxygen. With the aid of Table 2. It is illustrated that $1 \mathrm{~kg}$ of carbon (C) will produce $1.333 \mathrm{Kg}$ of Methane, which is applied to the yearly output of carbon produced. Therefore the yearly Methane obtained from MSW is demonstrated in the Figure 4 below:

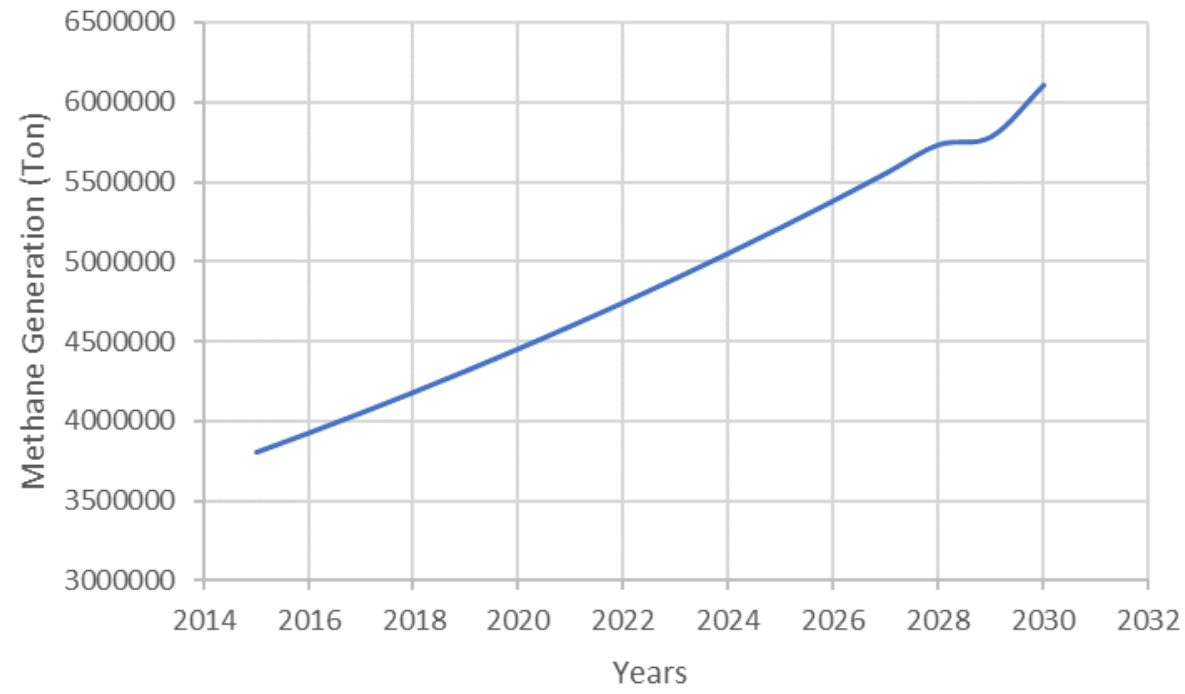

Figure 4. Estimation of Methane obtained from chemical reaction 
It can be depicted from the Figure 4 that Methane production from chemical reaction of Carbon with water under thermodynamically stable condition yields an increasing production of Methane which increases steadily each year as a result of increasing release of carbon constituent form solid waste.

\section{Estimation of Energy Generation Potential}

To determine energy generation potential from MSW, mass burn incineration is adopted where total waste is considered. However due to the high moisture content in Lagos State waste created by lack of proper sorting method and waste disposal. It is assumed 35\% of total wastes/day as expressed in Table 1 is dry waste. Where the energy content in various waste material are expressed in the Table 4 where the last two column depicts the total energy content and lower heating value (LHV) of waste constituent.

Table 4. Energy content of different waste constituents [14]

\begin{tabular}{|c|c|c|}
\hline Material & $\mathrm{Kwh} / \mathrm{Kg}$ in material & $\mathrm{Kwh} / \mathrm{Kg}$ in waste \\
\hline Paper & 4.39 & 1.21 \\
\hline Plastic & 9.05 & 0.46 \\
\hline Glass & 0.00 & 0.00 \\
\hline Textile & 5.20 & 0.22 \\
\hline Organic matter & 1.55 & 0.10 \\
\hline Others & 3.36 & 0.28 \\
\hline
\end{tabular}

Total energy content of mass burn can be depicted from the energy content of waste constituent, Table 4 as $2.27(\mathrm{Kwh} / \mathrm{Kg})$. Therefore for a ton of MSW considering the waste structure of Lagos state as expressed in Figure 2, it can be easily interpreted that a ton of MSW contains $313.4 \mathrm{Kwh} /$ day energy content. Energy recovery potential (ERP) is expressed in Gwh/day as adopted by [14]:

$$
\operatorname{ERP}\left(\frac{G W h}{d a y}\right)=\left(\text { Drywaste }\left(\frac{K g}{\text { day }}\right) x \text { LHVofwaste }\left(\frac{K W h}{K g}\right)\right)
$$

Adopting the expression in Eq. (2) with respect to the above stated condition the energy recovery potential from MSW can be expressed as Figure 5.

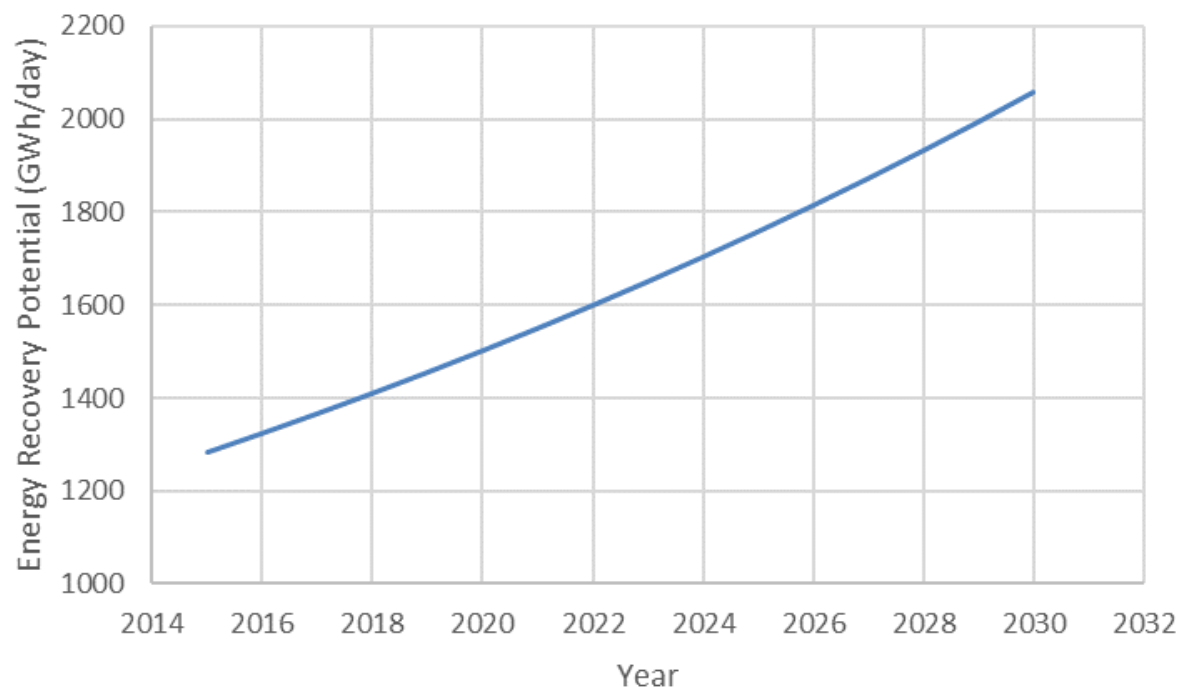

Figure 5. Energy recovery potential forecast for Lagos metropolis 
As observed in the energy recovery potential (ERP) Figure 5, it is evident that despite low dry waste, the energy potential is sufficiently high for daily generation, which increases steadily for year output production. The net generation potential (NGP) for electrical power is defined as [14]:

$$
N G P=\eta P G P=\eta x E R P x \frac{10^{3}}{24}
$$

Utilizing electrical power efficiency as low as $18 \%$. Substituting values of appropriate parameters into the Eq. 3.The NGP forecast is expressed for yearly output as Figure 6.

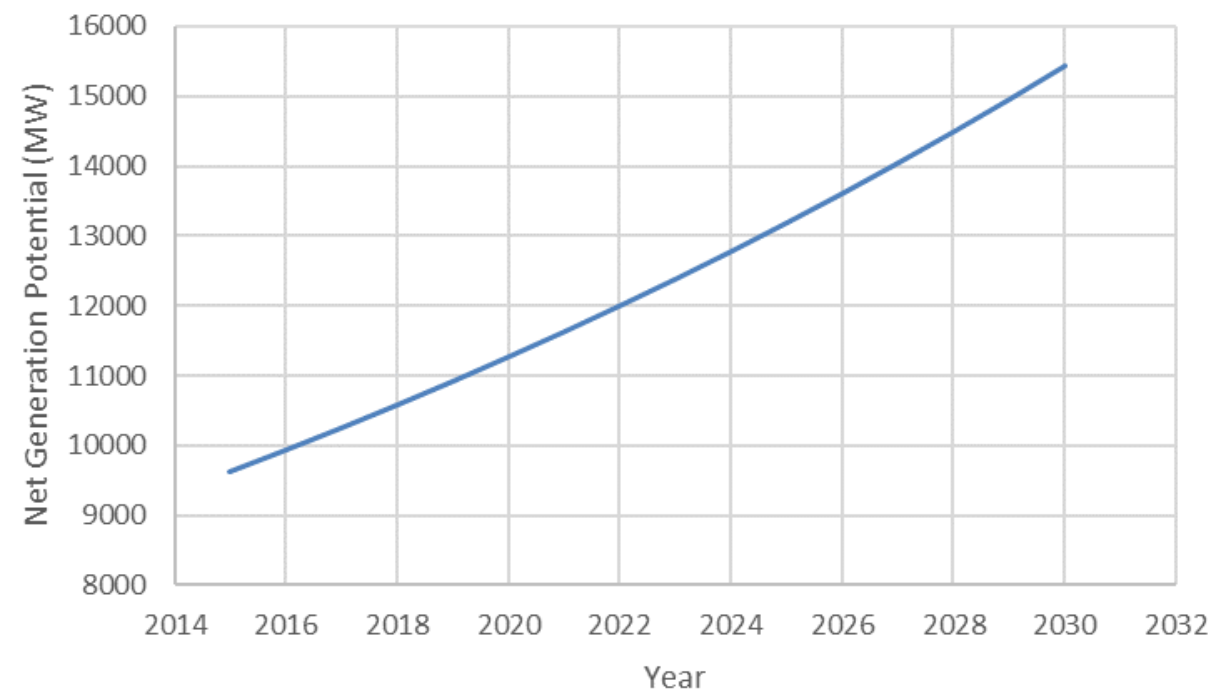

Figure 6. Net generation potential forecast for Lagos metropolis

Figure 6 illustrates a promising power generation potential from MSW for the Lagos community, where it is observed that a high power potential of over 10,000 MW of power from year 2016 can be obtained through MSW. Rather than the mass burning of waste in landfills creating atmospheric pollution and other forms of environmental degradation with no particular benefit obtained from the huge solid waste. More so it is observed that Figure 6 follows almost a linear trend; this is due to earlier assumptions of constant average waste generation with population growth rate as it affects MSW production.

\section{Economic Viability of the Waste to Energy Technology (WTE)}

Since energy generation from municipal solid waste is highly intensive, especially processing cost of waste. There is need to analyze cost requirements and compare the cost involved with other relevant energy resource. Therefore comparison with fossil fuel oil based energy is considered. Since this is one of the major source of power generation in Nigeria.

Table 5. Processing cost of waste treatment

\begin{tabular}{|c|c|}
\hline Waste treatment cost/tonnage & Cost (NGN Naira) \\
\hline Separation of waste & 100.00 \\
\hline Drying of waste & 250.00 \\
\hline Storage of waste/day & 150.00 \\
\hline Total Cost & 500.00 \\
\hline
\end{tabular}


Table 6. Determination of substitution effect of waste to fuel oils

\begin{tabular}{c|c|c|}
\hline 1 Tonnage of processed waste(A) & N500.00 \\
\hline${ }^{\text {aRDF available for purchase(B) }}$ & 4500.834 tons \\
\hline Cost of RDF (A x B) & N2,250,417 \\
\hline${ }^{b}$ Energy derivable in RDF (C) & $313.4 \mathrm{Kwh} /$ ton \\
\hline Energy obtained from RDF (B x C) & $1,410,561.38 \mathrm{Kwh}$ \\
\hline${ }^{[18]}$ Energy derivable from Diesel Oil & $100 \mathrm{Kwh} / \mathrm{tr}$ \\
\hline \multicolumn{2}{|c|}{ Cost of Diesel Oil substitute (D) } & $\mathrm{N} 2,821,122$ \\
\hline Variation of fuel substitute[(A x B)-D] & $\mathrm{N} 570,705$ \\
\hline a. 35\% of waste generation per day as at year 2018, b. See estimation of energy potential section
\end{tabular}

Table 6 illustrates energy derivable from MSW/day from the Lagos State metropolis compared with diesel fuel oil. As observed from analysis despite high processing cost of MSW demonstrated in Table 5, it still proves favorable against fossil fuel oil.

\section{CONCLUSION}

In many growing cities where population rate over shoots infrastructural development. Solid wastes, a domestic energy resource with the potential to provide a significant amount of energy [2], is often over looked and pushed aside. Taking 2016 as a reference, it is illustrated that there is an energy recovery potential of over 1300 GW/day with a high power potential of over 10,000 MW of power. This is observed to only increase due to corresponding increase in population of the metropolis over the years as well as solid waste. This is not to spell doom but to create a channel of alternative resource for the Lagos metropolis if the various landfill sites can be converted to waste to energy (WTE) technology sites and in turn energy resources can be harnessed for other uses to serve the growing population. In this article, a relationship between the parameters that makes up a proximate analysis with energy content of MSW and its conversion to power is presented.

\section{FUNDING STATEMENT}

The authors received no funds/ support or grants from any body or institution as regards paper publication.

\section{CONFLICT OF INTERESTS STATEMENT}

The authors declare no conflicting interest as regards publication of this study.

\section{REFERENCES}

[1] Tsai, W. and Kuo K. (2010). An analysis of power generation from municipal solid waste (MSW) incineration plants in Taiwan. Energy, 35, 4824-4830.

[2] Kathirvale, S., Yurus, M.N.M., Sopian K. and Samsuddin, A.H. (2003). Energy potential from municipal solid waste in Malaysia. Renewable Energy, 29, 559-56.

[3] Murphy, J.D. and Mckeogh, E. (2004). Technical economic and environmental analysis of energy. Renewable Energy, 29, 1043-1057.

[4] Singh, R.P., Tyagi, V.V., Allen, T., Ibrahim, M.H. and Kothari, R. (2011). An overview for exploring the possibilities of energy generation from municipal solid waste (MSW) in Indian scenario. Renewable and Sustainable Energy Reviews. 15, 4797-4808.

[5] Omari, A.M. (2013). Characterization of municipal solid waste for energy recovery. Journal of Multidisciplinary Engineering Science and Technology, 2, (1) 230-237.

[6] Green, A.E.S. and Zimmerman, A.R. (2013). Energy solid waste advanced thermal engineering, In Encyclopedia management, Taylor and Francis, New York.

[7] Porteous, A., (2011). Energy from waste incineration- a state of the art emission review with an emphasis on public acceptability. Resource recovery and conservation, DOI: S0306-2619(01)00021-6, 2011.

[8] Sheng, H.P. and Alter, H. (1975). Energy recovery from municipal solid waste and method of comparing refusederived fuel, Resource Recovery and Conservation, 1, 85-93. 
[9] Haley, C.A.C. (1990). Energy recovery from burning municipal solid wastes: a review. Resources, Conservation and Recycling, 4, 77-103.

[10] Kalanatarifard, A., (2012). Identification of municipal solid waste characteristics and potential of plastic recovery at Bakri landfill, Muar, Malaysia. Journal of Sustainable Development, 5 (7), 35-47.

[11] Gohlke, O. (2009). Efficiency of energy recovery from municipal solid waste and the resultant effect on the greenhouse gas balance. Waste management resources. DOI: 10.1177/0734242X09349857, 2009.

[12] Themelis, N.J., Kim, Y.H. and Bradpy, M.H. (2002). Energy recovery from New York City municipal solid waste. Waste Management and Research, 20, 223-233.

[13] Lagos State Waste Management Authority; www.lawma.gov.ng

[14] Ouda, O.K.M., Raza, S.A., Al-Waked, R., Al-Asad, J.F. and Nizami, A. (2015). Waste to energy potential in the province of Saudi Arabia. Journal of King Saud University, Doi.org/10/1016/j.ksues.2015.02.002,2015.

[15] Lagos State Bureau of Statistics; www.lagosstate.gov.ng

[16] Tchobanoglaus, G., Theisen, H. and Eliassen, R. (1977). Solid waste: Engineering principles and management issues. McGraw-Hill, New York.

[17] Niessen, W.R., (2002). Combustion and incineration processes. Marcel Dekker Incorporated, New York.

[18] Energy conservation and environmental protection; www.e-education.psu.edu

[19] Koten, H., (2018). Performance analysis of a diesel engine within a multidimensional framework. Journal of Thermal Engineering. 4(4), 2075-2082.

[20] Abay, M., Colak, A.U., Yukset, L., (2018). Computational fluid dynamics analysis of flow and combustion of a diesel engine. Journal of Thermal Engineering, 4 (2), 1878-1895.

[21] Dehini, R. and Berbaoul B., (2018). Solar energy control and power quality improvement using multilayered feed forward neural network. Journal of Thermal Engineering, 4 (3), 2018. 